Summary These children had neck bruising consistent with being held around the neck (Table 1). There were no serious consequences. 2 children sustained injuries when restrained by teachers, one disabled child throttled by step-dad for not going to bed. 3 cases were associated with domestic violence.

Conclusions When there are suspicions of attempted strangulation Child protection procedures should be followed even if there are no visible injuries was the child would continue to be at risk of harm.

Teachers should review their practice of restraint when dealing with violent children.

Adolescent girls, can be subjected to severe domestic abuse from their partners with of serious consequences.

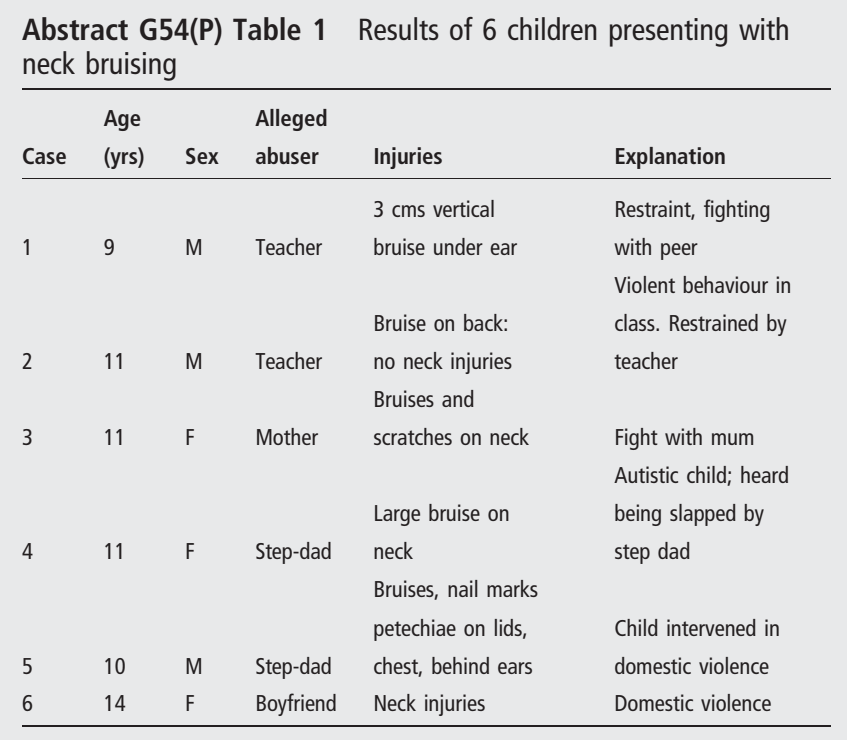

More research on the long-term effects of children experiencing strangulation is required.

\section{G55(P) FEMALE GENITAL MUTILATION: A SURVEY OF AWARENESS, TRAINING AND CURRENT PRACTICE}

TL Roberts, X Poblete. Community Child Health, Northwick Park Hospital, London, UK

\subsection{6/archdischild-2015-308599.54}

Background "Tackling FGM in the UK", Intercollegiate document calls for paediatricians to routinely ask about FGM in their clinical history to identify girls and young women who are at risk and require safeguarding.

Aims To gather paediatricians' views at a large district general hospital on awareness, training and current practice regarding female genital mutilation.

Methods A pilot survey using Monkey Survey was compiled and sent out to paediatric registrars (ST3-ST8) which was followed by a survey to all paediatricians in the department. Questions included multiple choice and open ended format.

Results Out of 105 invitations 32 responses (30\%) were received from 9 consultants, 19 paediatric trainees, 4 unknown. Most of those answering reported "some" knowledge about FGM (88\%) although only 6\% said they had "adequate" knowledge. The source of information was through professional teaching in $66 \%$ and by the media in $34 \%$. Only half of the sample (58\%) thought FGM to be a cultural issue but most $(97 \%)$ thought FGM to be a safeguarding issue. Of the 32 responses
$53 \%$ had looked after a patient either who had been subjected to FGM themselves or with a mother/sister known to be affected. Open questions garnered comments on how doctors became aware of FGM in patient or female relatives; the confidence required to ask about FGM in history taking and management of suspected cases.

Conclusions The findings of this survey represent the views of a small number of paediatricians in a general hospital. The poor response rate could suggest lack of awareness of FGM or that surveys are not a way of gathering the views of busy paediatricians. Paediatricians taking part felt almost unanimously that FGM is a safeguarding issue although there was less certainty about cultural issues. The survey identified a significant training need to help paediatricians identify and manage possible cases of FGM.

\section{G56(P) FEMALE GENITAL MUTILATION: KNOWLEDGE, TRAINING AND EXPERIENCE OF HEALTHCARE PROFESSIONALS AT A LONDON HOSPITAL}

${ }^{1} \mathrm{R}$ Gabrasadig, ${ }^{2} \mathrm{~F}$ Asamoah, ${ }^{3} \mathrm{~N}$ Wilson. ${ }^{1}$ Paediatrics, Barts Health, London, UK; ${ }^{2}$ Research and Development Department, Homerton Hospital, London, UK; ${ }^{3}$ Wonder Foundation, London, UK

\subsection{6/archdischild-2015-308599.55}

The World Health Organisation defines female genital mutilation (FGM) as "procedures that involve partial or total removal of the external female genitalia, or other injury to the female genital organs for non-medical reasons." Since 1985 it has been a criminal offence in the UK to perform FGM, or to assist a girl in performing FGM on herself.

This study was based at a district general hospital in London with a high prevalence of patients originating from countries where FGM is practiced. We aimed to assess healthcare professionals' knowledge and confidence in managing FGM, as this underpins their ability to respond adequately to the medical needs of patients with FGM and safeguard girls and young women from the practice.

A confidential survey was distributed within the hospital from January-March 2014. 157 healthcare professionals responded. $35 \%$ were midwives $(\mathrm{n}=51), 45 \%$ medical doctors $(\mathrm{N}=71)$, $19 \%$ nursing $(\mathrm{N}=30), 3 \%$ other $(\mathrm{N}=5)$.

$100 \%$ of respondents stated they knew what FGM was and $71.4 \%$ felt they would benefit from further training on the subject. Only 21\% of respondents stated that they would feel comfortable discussing FGM with patients. Most healthcare professionals had not read any guidelines relating to FGM (65.3\%). Midwives were more likely to have read guidelines compared with any other profession $(\mathrm{p}=0.001)$.

Interestingly, $73 \%$ felt there were barriers that prevent healthcare professionals from speaking to patients about FGM. On a scale of $1-5(1=$ not important at all, to $5=$ very important $)$, lack of knowledge of FGM was rated as the most important barrier with a mean rating of 4.3 out of 5 , followed by a language barrier (rating $=4.1$ ) and fear of appearing culturally insensitive (rating $=3.9$ ).

We have identified what are perceived by healthcare professionals to be the most significant barriers to discussing FGM with patients. We suggest that future training should particularly focus on overcoming these barriers. One potential approach would be specialised communication training provided by people who are already familiar with working with women who have suffered FGM. These barriers should be addressed if we are to 